CLINICAL STUDY

\title{
Circulating levels of IGF 1 are associated with muscle strength in middle-aged- and oldest-old women
}

\author{
Diana G Taekema ${ }^{1,2}$, Carolina H Y Ling ${ }^{1}$, Gerard Jan Blauw ${ }^{1}$, Carel G Meskers ${ }^{3}$, Rudi G J Westendorp ${ }^{1,4}$, \\ Anton J M de Craen ${ }^{1,4}$ and Andrea B Maier ${ }^{1,4}$ \\ ${ }^{1}$ Department of Gerontology and Geriatrics, C2-R-133, Leiden University Medical Center, PO Box 9600, 2300 RC, Leiden, The Netherlands, ${ }^{2}$ Department \\ of Geriatrics, Rijnstate Hospital, PO Box 9555, 6800 TA, Arnhem. The Netherlands and ${ }^{3}$ Department of Rehabilitation Medicine and ${ }^{4}$ Netherlands \\ Consortium for Healthy Aging, Leiden University Medical Center, PO Box 9600, 2300 RC, Leiden, The Netherlands \\ (Correspondence should be addressed to D G Taekema at Department of Gerontology and Geriatrics, C2-R-133, Leiden University Medical Center; \\ Email: d.g.taekema@lumc.nl)
}

\begin{abstract}
Objective: In aging populations, poor handgrip strength has been associated with physical disability and mortality. IGF1 is an important mediator of muscle growth and regeneration affecting muscle function. We studied the relationship between circulating levels of IGF1, its binding protein 3 (IGFBP3), and handgrip strength and physical performance in middle-aged- and oldest-old subjects.

Design: Cross-sectional analysis in two different cohorts composed of middle-aged- $(n=672$, mean $63.9 \pm 6.7$ years $)$ and oldest-old subjects $(n=272$, all 89 years $)$.

Methods: Handgrip strength, functional performance and ability, and serum levels of IGF1 and IGFBP3 were measured in all subjects and analyzed by linear regression for men and women separately. Results: IGF1 and IGFBP3 levels declined with chronological age and were positively associated with handgrip strength in middle-aged- and oldest-old women (both, $P<0.05$ ), but not in men of either age group. Furthermore, higher serum levels of IGF1 were associated with slower walking speed in oldestold men $(P=0.012)$, and serum levels of IGFBP3 were positively associated with activities of daily living in the oldest-old women $(P=0.002)$.

Conclusion: The significant relationship between IGF1 levels and muscle strength found in women but not in men suggests a gender-specific influence of IGF1 on muscle strength. Further studies are necessary to test the relationship with physical performance.
\end{abstract}

European Journal of Endocrinology 164 189-196

\section{Introduction}

Aging is associated with a decline in muscle mass, commonly referred to as sarcopenia. Sarcopenia is a major determinant of muscle strength loss in the elderly. Poor muscular strength is in turn associated with adverse outcomes, such as physical disability and mortality (1-3). Depending on the definition used, the prevalence of sarcopenia is reported to be as high as $60 \%$ in the general oldest-old population over 85 years of age (4). By 2050, oldest-old subjects will account for one-fifth of all older persons globally (5). In view of the detrimental functional effects, sarcopenia may have on the quality of life and survival of our aging societies; research into its etiology is important for optimization of preventive and therapeutic strategies.

The pathophysiology of sarcopenia is complex and involves interplay of multiple factors including chronic diseases, inflammatory, metabolic, nutritional, and hormonal factors (4). With regard to hormonal factors, evidence increasingly suggests an association between age-dependent decline in levels of growth hormone (GH) and insulin-like growth factor 1 (IGF1), the major mediator of GH action, with unfavorable changes in body composition with age $(6,7)$. Moreover, the reduction in physical activity also contributes to the decline in GH secretion and alteration in body composition during aging (6). Both GH and IGF1 have important anabolic effects on skeletal muscle tissue. IGF1 has been shown to stimulate muscle cell proliferation and differentiation, facilitate muscle protein synthesis, and inhibit its degradation (8).

Previous studies have assessed the association between IGF1 and IGF-binding protein 3 (IGFBP3) and functional outcome in older people. Low serum levels of IGF1 and IGFBP 3 were reported to be associated with poorer muscular strength, walking speed, mobility tasks, various physical performance, and all-cause mortality in the elderly (9-12). GH therapy has been associated with increased lean body mass and decreased fat mass (13-15), but evidence is still lacking on its effectiveness in improving muscle function and overall 
physical performance in the old. However, aforementioned studies were not consistent in their findings and did not include the group of the oldest-old subjects.

More research is needed to assess the association between these hormonal factors and muscle function, overall physical performance and disability. We assessed this relationship in two different age groups composed of middle-aged- and oldest-old subjects. We hypothesized that lower levels of IGF1 are associated with lower muscle strength in middle-aged- and oldest-old subjects, and that lower levels of IGF1 are associated with impaired physical performance and disability in the oldest-old subjects.

\section{Method}

\section{Subjects}

Data for the middle-aged- and oldest-old subjects were obtained from the Leiden Longevity Study and Leiden 85-plus Study respectively. In the Leiden Longevity Study, 420 families consisting of long-living Caucasian siblings together with their middle-aged-old offspring and the partners thereof were recruited (16). This study included 672 of the middle-aged-old offspring and their partners. All subjects visited the study center where measurements were performed. The Leiden 85-plus Study is a community-based prospective follow-up study of inhabitants of the city of Leiden, The Netherlands (17). Enrollment took place between 1997 and 1999. All inhabitants who reached the age of 85 years were eligible to participate $(n=599)$. Subjects were visited annually at their place of residence where various tests were performed. Follow-up continued until death or 90 years of age. The current study included 272 oldest-old subjects who were alive at the age of 89 years. There were no selection criteria on health or demographic characteristics in both studies $(16,17)$. The medical ethical committee of the Leiden University Medical Centre approved both studies. Informed consent was obtained from all subjects. In case of severe cognitive impairment, a guardian gave informed consent.

\section{Subject characteristics and possible confounders}

Anthropometric data was collected from all subjects. At baseline, information on common chronic diseases and medication use was obtained from the general practitioner, pharmacist's records and blood sample analysis. Information on menopausal state and past and current use of hormone replacement therapy in the middle-aged-old women was assessed by a questionnaire at baseline. The chronic diseases recorded were diabetes mellitus, chronic obstructive pulmonary disease, malignancy, myocardial infarction, stroke, and hypertension. For each subject, a sum score of chronic diseases (defined as comorbidity) was assigned.

\section{Serum parameters}

Since systemic inflammation is negatively associated with serum levels of IGF1 (18), serum C-reactive protein (CRP) levels were measured as a proxy for systemic inflammation. Serum levels of IGF1, IGFBP3, and CRP were determined in the middle-aged-old subjects and at the age of 89 years in the oldest-old subjects. In both studies, IGF1 and IGFBP3 were determined using the automated Immulite 2500 from DPC (Los Angeles, CA, USA). CRP was measured with a standard, fully automated P800 Modular system (Roche) with a sensitivity ranging from $1 \mathrm{mg} / \mathrm{l}$ in the oldest-old subjects to $0.6 \mathrm{mg} / \mathrm{l}$ in the middle-aged-old subjects. The increased sensitivity in the middle-aged-old subjects is explained by improvements to the CRP assay in later models of the analyzer.

\section{Handgrip strength}

Handgrip strength was used as a proxy for global muscle strength $(19,20)$ and was measured using a Jamar hand dynamometer (Sammons Preston, Inc., Bolingbrook, IL, USA) to the nearest kilograms. Measurement of handgrip strength is a reliable instrument and has been tested in different age groups, including oldest-old subjects (21-23). All subjects were instructed to maintain an upright standing position, arms down by the side, and holding the dynamometer in the dominant hand without squeezing the arm against the body. The width of the dynamometer's handle was adjusted to the hand size of the subjects such that the middle phalanx rested on the inner handle. Subjects were allowed to perform one test trial, followed by three trials, and the best measure was taken for analysis. Handgrip strength was measured at one time point in the middle-aged-old subjects and at the age of 89 years in the oldest-old subjects.

\section{Measurements of functional ability in oldest-old subjects}

Functional ability was measured only in the group of oldest-old subjects. Competence in the activities of daily living (ADL) was measured in the oldest-old subjects with the Groningen Activity Restriction Scale (GARS) that assesses nine areas of basic ADL and instrumental ADL (IADL) respectively (24). The sum scores for the ADL and IADL range from 9 (competent in all activities) to 36 (unable to perform any activity without help) respectively, and their sum scores together give the total GARS score. Walking speed was assessed in the oldest-old subjects by a standardized $6 \mathrm{~m}$ walking test, which was validated in previous longitudinal aging studies (25). Subjects were instructed to walk two laps of $3 \mathrm{~m}$ each as quickly as possible. The time it took for the subjects to walk the total $6 \mathrm{~m}$ was recorded in seconds, using a stopwatch. The use of a walking aid was allowed during the test. 


\section{Statistical analysis}

Data were analyzed separately for men and women. The association between IGF1, IGFBP3 and handgrip strength was analyzed by linear regression using three different models. In model 1 , the analysis was adjusted for height, weight, and age for the middle-aged-old subjects and height and weight for the oldest-old subjects. Models 2 and 3 were adjusted for the same covariates as for model 1 with further adjustments for CRP and comorbidity respectively. In addition, the population of middle-aged-old women was stratified by menopausal state, and all linear regression analyses were repeated. SPSS 17.0 (SPSS Inc., Chicago, IL, USA) for Windows was used for all analyses. $P$ values $<0.05$ were considered statistically significant.

\section{Results}

\section{Subjects' characteristics}

Baseline characteristics of the study subjects are presented in Table 1. Mean age of the middle-aged-old subjects was 64.3 years, and the age of the oldest-old subjects was 89 years. Height, weight, and handgrip strength were significantly higher in men and overall lower in the oldest-old subjects. As expected, the oldestold subjects had a higher number of chronic diseases. IGF1 and IGFBP 3 levels were lower in the oldest-old subjects than in the middle-aged-old subjects $(P<0.001)$. For both the middle-aged- and oldest-old subjects, there were no significant gender differences in the serum IGF1 levels, but women had significantly higher IGFBP3 levels than men in both studies $(P<0.001)$.

Information on menopausal status was available for 325 out of 339 middle-aged-old women. Postmenopausal state, defined as cessation of menstrual period for at least 1 year, was present in 288 (88.6\%) women.
Of these, only five (1.5\%) women were current users of hormone replacement therapy. Of the $22(6.8 \%)$ perimenopausal middle-aged-old women, there were three $(0.9 \%)$ current users of hormone replacement therapy.

\section{Serum levels of IGF1, IGFBP3, and handgrip strength}

The multiple regression models for the association between IGF1, IGFBP3 levels and handgrip strength in the middle-aged- and oldest-old subjects are presented in Tables 2 and 3 respectively. Serum levels of IGF1 were significantly associated with higher handgrip strength in the middle-aged-old women after adjusting for age, height, and weight $(0.11 \mathrm{~kg}$ higher handgrip strength per $1 \mathrm{mmol} / \mathrm{l}$ increase in IGF1 level, $P=0.049$ ). However, significance was lost after adjustment for CRP and comorbidity. No significant association was observed between handgrip strength and IGF1 in men and IGFBP 3 in both genders. In addition, we stratified the group of middle-aged-old women by menopausal status and repeated all linear regression analyses.

IGF1 was positively associated with handgrip strength in the postmenopausal middle-aged-old women $(0.13 \mathrm{~kg}$ higher handgrip strength per $1 \mathrm{mmol} / \mathrm{l}$ increase in IGF1, $P=0.037$ ) but not in premenopausal and perimenopausal women. The association did not change with adjustment for CRP $(0.12 \mathrm{~kg}$ higher handgrip strength per $1 \mathrm{mmol} / \mathrm{l}$ increase in IGF $1, P=0.040)$. In postmenopausal middle-aged-old women, IGF1 was positively associated with handgrip strength in the fully adjusted model $(0.15 \mathrm{~kg}$ higher handgrip strength per $1 \mathrm{mmol} / \mathrm{l}$ increase in IGF1, $P=0.013$ ), but not in premenopausal and perimenopausal women. After exclusion of women receiving hormone replacement therapy, these

Table 1 Baseline characteristics of study subjects.

\begin{tabular}{|c|c|c|c|c|c|c|}
\hline & \multicolumn{3}{|c|}{ Middle-aged-old $(n=672)$} & \multicolumn{3}{|c|}{ Oldest-old ( $n=272)$} \\
\hline & $\begin{array}{c}\text { Men } \\
(n=333)\end{array}$ & $\begin{array}{l}\text { Women } \\
(n=339)\end{array}$ & $P$ value & $\begin{array}{c}\text { Men } \\
(n=74)\end{array}$ & $\begin{array}{l}\text { Women } \\
(n=198)\end{array}$ & $P$ value \\
\hline Age (years; mean, s.D.) & $64.3(6.5)$ & $61.6(6.6)$ & $<0.001$ & 89.0 & 89.0 & - \\
\hline Height (m; mean, s.D.) & $1.78(0.1)$ & $1.66(0.1)$ & $<0.001$ & $1.68(0.1)$ & $1.56(0.1)$ & $<0.001$ \\
\hline Weight (kg; mean, s.D.) & $85.5(11.3)$ & $72.6(12.7)$ & $<0.001$ & $71.7(12.1)$ & $65.8(12.8)$ & $<0.001$ \\
\hline \multicolumn{7}{|l|}{ Chronic diseases $(n, \%)$} \\
\hline Diabetes mellitus & $27(8.1)$ & $14(4.1)$ & 0.080 & $7(9.5)$ & $27(13.6)$ & 0.356 \\
\hline COPD & $15(4.5)$ & $9(2.7)$ & 0.247 & $8(10.8)$ & $16(8.1)$ & 0.482 \\
\hline Malignancy & $21(6.3)$ & $23(6.8)$ & 0.015 & $13(17.6)$ & $24(12.1)$ & 0.245 \\
\hline Hypertension & $80(24.0)$ & $86(25.4)$ & $<0.001$ & $27(36.5)$ & 79 (39.9) & 0.609 \\
\hline Myocardial infarction & $12(3.6)$ & $2(0.6)$ & 0.021 & $21(28.4)$ & $29(14.6)$ & 0.009 \\
\hline Stroke & $11(3.3)$ & $5(1.5)$ & 0.021 & $6(8.1)$ & $11(5.6)$ & 0.477 \\
\hline \multicolumn{7}{|l|}{ Serum parameters } \\
\hline IGFBP3 (mg/l; mean, s.D.) & $4.3(0.9)$ & $4.5(0.9)$ & $<0.001$ & $2.6(1.0)$ & $3.3(0.9)$ & $<0.001$ \\
\hline CRP (mg/l; median, IQR) & $1.2(0.7-2.4)$ & $1.3(0.7-3.1)$ & 0.017 & $3.0(1.0-6.0)$ & $3.0(1.0-7.0)$ & 0.903 \\
\hline
\end{tabular}

COPD, chronic obstructive pulmonary disease; IQR, interquartile range. Comparison between groups by ANOVA. 
Table 2 Serum IGF1 and IGFBP3 levels as determinants of handgrip strength in middle-aged-old men and women.

\begin{tabular}{|c|c|c|c|c|c|c|}
\hline & \multicolumn{6}{|c|}{ Handgrip strength (kg) } \\
\hline & \multicolumn{3}{|c|}{ Men $(n=333)$} & \multicolumn{3}{|c|}{ Women $(n=339)$} \\
\hline & $\beta$ & S.E.M. & $P$ value & $\beta$ & S.E.M. & $P$ value \\
\hline \multicolumn{7}{|l|}{ IGF1 (mmol/l) } \\
\hline Adjusted for age, height, and weight & -0.01 & 0.09 & 0.929 & 0.11 & 0.06 & 0.049 \\
\hline Additional adjustment for CRP & -0.01 & 0.09 & 0.921 & 0.11 & 0.06 & 0.051 \\
\hline Additional adjustment for comorbidity ${ }^{\mathrm{a}}$ & -0.08 & 0.10 & 0.406 & 0.11 & 0.06 & 0.054 \\
\hline \multicolumn{7}{|l|}{ IGFBP3 (mg/l) } \\
\hline Adjusted for age, height, and weight & 0.07 & 0.45 & 0.870 & 0.38 & 0.33 & 0.243 \\
\hline Additional adjustment for CRP & 0.06 & 0.46 & 0.902 & 0.36 & 0.33 & 0.272 \\
\hline Additional adjustment for comorbidity ${ }^{\mathrm{a}}$ & -0.07 & 0.49 & 0.889 & 0.24 & 0.34 & 0.477 \\
\hline
\end{tabular}

$\beta$, estimate.

${ }^{a}$ For each subject, a sum score of chronic diseases (defined as comorbidity) was assigned. Chronic diseases included diabetes mellitus, chronic obstructive pulmonary disease, malignancy, myocardial infarction, stroke, and hypertension.

associations remained significant in the postmenopausal middle-aged-old women $(0.13 \mathrm{~kg}$ higher handgrip strength per $1 \mathrm{mmol} / \mathrm{l}$ increase in IGF $1, P=0.037$ ). No significant associations were found between IGFBP 3 and handgrip strength according to menopausal status (all, $P>0.05$ ).

Serum IGF1 levels were significantly associated with higher handgrip strength in the oldest-old women $(0.19 \mathrm{~kg}$ higher handgrip strength per $1 \mathrm{mmol} / \mathrm{l}$ increase in IGF1 level, $P=0.027$ ) but not in men. After adjustment for CRP and comorbidity, the association remained significant $(P=0.023$ and $P=0.029$, respectively). Moreover, serum levels of IGFBP 3 were also significantly associated with higher handgrip strength in women only $(1.56 \mathrm{~kg}$ higher handgrip strength per $1 \mathrm{mg} / \mathrm{l}$ increase in IGFBP3 level, $P<0.001)$. Further adjustments did not change this association.

\section{Serum levels of IGF1, IGFBP3, and functional performance and ability}

Table 4 shows the multiple regression models for the association between serum levels of IGF1 and IGFBP3 and ADL and walking speed in the oldest-old subjects. No association was observed between serum levels of IGF1 and ADL in both genders. Serum levels of IGFBP3 were positively associated with the GARS scores in the oldest-old women (3.17 points better GARS score per $1 \mathrm{mg} / \mathrm{l}$ increase in IGFBP3 level, $P=0.002$ ), but statistical significance was not reached in men. An inverse association was observed between serum IGF1 levels and walking speed in the oldest-old men $(1.28 \mathrm{~s}$ slower walking speed per $1 \mathrm{mmol} / \mathrm{l}$ increase in IGF 1 level, $P=0.012$ ). There was no significant association between walking speed and serum levels of IGFBP3 in both genders.

\section{Discussion}

We hypothesized that lower levels of anabolic factor IGF1 are associated with lower muscle strength in the middle-aged- and oldest-old subjects. Moreover, we hypothesized that lower serum levels of IGF1 are associated with impaired physical performance and disability in the oldest-old men and women. Our results

Table 3 Serum IGF1 and IGFBP3 levels as determinants of handgrip strength in oldest-old men and women.

\begin{tabular}{|c|c|c|c|c|c|c|}
\hline & \multicolumn{6}{|c|}{ Handgrip strength $(\mathrm{kg})$} \\
\hline & \multicolumn{3}{|c|}{ Men $(n=74)$} & \multicolumn{3}{|c|}{ Women $(n=198)$} \\
\hline & $\beta$ & S.E.M. & $P$ value & $\beta$ & S.E.M. & $P$ value \\
\hline \multicolumn{7}{|l|}{ IGF1 (mmol/l) } \\
\hline Adjusted for height and weight & 0.10 & 0.19 & 0.690 & 0.19 & 0.08 & 0.027 \\
\hline Additional adjustment for CRP & -0.10 & 0.21 & 0.661 & 0.21 & 0.09 & 0.023 \\
\hline Additional adjustment for comorbidity ${ }^{a}$ & 0.07 & 0.20 & 0.734 & 0.19 & 0.09 & 0.029 \\
\hline \multicolumn{7}{|l|}{ IGFBP3 (mg/l) } \\
\hline Adjusted for height and weight & -0.50 & 1.00 & 0.094 & 1.56 & 0.37 & $<0.001$ \\
\hline Additional adjustment for CRP & 0.45 & 1.01 & 0.651 & 1.46 & 0.40 & $<0.001$ \\
\hline Additional adjustment for comorbidity ${ }^{\mathrm{a}}$ & 0.61 & 0.99 & 0.536 & 1.56 & 0.37 & $<0.001$ \\
\hline
\end{tabular}

$\beta$, estimate.

${ }^{a}$ For each subject, a sum score of chronic diseases (defined as comorbidity) was computed. Chronic diseases included diabetes mellitus, chronic obstructive pulmonary disease, malignancy, myocardial infarction, stroke, and hypertension. 
show that levels of IGF1 and IGFBP3, both decrease with age, and that they are positively associated with muscle strength in postmenopausal middle-aged- and oldest-old women, but not in men. Furthermore, we found that serum levels of IGF1 were negatively associated with walking speed in oldest-old men, and IGFBP3 serum levels were positively associated with ADL in oldest-old women.

IGF1 is one of the most important mediators of muscle growth and subsequent regeneration (26) affecting muscle performance due to its anabolic, hypertrophying signaling effect. IGF 1 is produced mainly in the liver, where its synthesis is GH dependent (27) but is also produced in multiple extrahepatic tissues acting in an autocrine and a paracrine fashion (28). Besides the age-dependent decline in IGF1 serum levels, tissue responsiveness to $\operatorname{IGF} 1(29,30)$ as well as intracellular signaling is less efficient with age (31). Previous studies have shown an association of IGF1 serum levels in the elderly and functional outcome parameters such as muscle strength $(10,32,33)$.

In agreement with other studies, we found a decrease in IGF1 and IGFBP3 levels with age, probably as a consequence of the decline in $\mathrm{GH}$ synthesis, in both male and female subjects (34-36). However, in contrast to recently published studies, we found no significant gender differences in IGF1 levels in the middle-aged- and oldest-old subjects $(37,38)$. Gender differences were present for IGFBP3 levels consistent with the findings of previous studies (39). The relationship between serum IGF1 levels and handgrip strength was present only in women. Two other studies concluded that handgrip strength and lower values for maximal muscle power and optimal shortening velocity were associated with lower circulating levels of IGF1 in women only $(32,40)$. More recently, IGF1 levels were associated with exercise capacity in healthy female volunteers (41). The missing positive relation in elderly men in our study might be partly explained by the lower IGF1 levels in men than in women. A recent study reported gender-specific reference ranges for different age groups (39). The serum levels of the oldest-old male subjects in our study were much lower than expected from the reference values (below 25th percentile). A possible explanation could be that lower levels of IGF1 are reflective of increased frailty in oldest-old men aged 89 years in our study cohort. Another reason for the absence of an association in elderly men could be that in men the decline in total hormonal burden is associated with detrimental outcome, rather than deficiency in a single hormone (42). Also sex hormones are strongly associated with muscle mass in men but not in women (40). Finally, the missing relationship between IGF1 levels and handgrip strength in oldest-old men could be explained by lack of power due to the limited number of oldest-old subjects; however, this does not explain why in the larger sample of middle-aged-old men the relation is also missing. More research is needed to point out possible underlying mechanisms of gender differences in IGF1 signaling and muscle strength.

The age-related decline in GH and IGF1 serum levels may promote frailty by contributing to the loss of muscle mass and strength. A significant positive relationship has been shown between low plasma IGF1 and functional outcome, such as impaired physical performance and self-reported difficulties with mobility tasks $(10,32,33)$. However, physical performance has also been found to be negatively associated with IGF1 serum levels $(13,35,43-45)$. Our findings regarding functional performance and ADL disability are also conflicting with higher IGF1 serum levels being associated with slower walking speed in oldest-old men and a positive association between serum levels of IGFBP3 3 and ADL in oldest-old women. This last

Table 4 Serum IGF1 and IGFBP3 levels as determinants of functional performance and ability in oldest-old men and women.

\begin{tabular}{|c|c|c|c|c|c|c|c|c|c|c|c|c|}
\hline & \multicolumn{6}{|c|}{ Activities of daily living $^{a}$ (points) } & \multicolumn{6}{|c|}{ Walking speed $(s)^{b}$} \\
\hline & \multicolumn{3}{|c|}{ Men $(n=74)$} & \multicolumn{3}{|c|}{ Women $(n=198)$} & \multicolumn{3}{|c|}{ Men $(n=74)$} & \multicolumn{3}{|c|}{ Women $(n=198)$} \\
\hline & $\beta$ & S.E.M. & $P$ value & $\beta$ & S.E.M. & $P$ value & $\beta$ & S.E.M. & $P$ value & $\beta$ & S.E.M. & $P$ value \\
\hline \multicolumn{13}{|l|}{ IGF1 (mmol/l) } \\
\hline Adjusted for height and weight & -0.33 & 0.3 & 0.324 & -0.27 & 0.2 & 0.240 & 1.28 & 0.5 & 0.012 & 0.08 & 0.2 & 0.688 \\
\hline Additional adjustment for CRP & -0.21 & 0.4 & 0.568 & -0.31 & 0.3 & 0.238 & 1.51 & 0.6 & 0.011 & 0.14 & 0.3 & 0.578 \\
\hline $\begin{array}{l}\text { Additional adjustment for } \\
\text { comorbidity }^{\mathrm{C}}\end{array}$ & -0.35 & 0.3 & 0.292 & -0.27 & 0.2 & 0.234 & 1.28 & 0.5 & 0.013 & 0.09 & 0.2 & 0.644 \\
\hline \multicolumn{13}{|l|}{ IGFBP3 (mg/l) } \\
\hline Adjusted for height and weight & -2.73 & 1.6 & 0.099 & -3.17 & 1.0 & 0.002 & 1.84 & 2.6 & 0.475 & 0.32 & 0.9 & 0.729 \\
\hline Additional adjustment for CRP & -2.66 & 1.9 & 0.158 & -3.00 & 1.1 & 0.009 & 2.78 & 3.0 & 0.367 & 0.60 & 1.1 & 0.601 \\
\hline $\begin{array}{l}\text { Additional adjustment for } \\
\text { comorbidity }^{\mathrm{C}}\end{array}$ & -2.88 & 1.6 & 0.083 & -3.17 & 1.0 & 0.002 & 1.79 & 2.6 & 0.484 & 0.34 & 0.9 & 0.706 \\
\hline
\end{tabular}


finding is consistent with an earlier study that found a potential positive influence of IGFI and IGFBP 3 in women with regard to walking speed and disability (10). Others have reported on the association between walking speed and IGF1 serum levels in 349 oldest-old subjects and found an association between IGF1 levels and walking speed only in 54 subjects with a body mass index above 30 (9). The finding that IGF1 levels are negatively associated with walking speed in oldest-old men is counterintuitive and is not supported by a limited number of earlier studies $(9,10)$. A chance finding in spite of the limited size of oldest-old men in this study cannot be excluded.

Despite these conflicting results, which could be explained by study population homogeneity with subsequent smaller ranges of IGF1 levels, the potential influence of GH/IGF1 on muscle function can best be illustrated by administration of these hormones. Acute administration of $\mathrm{GH}$ regulates muscle mitochondrial function by increasing the levels of several key mitochondrial proteins switching fuel utilization toward fat oxidation (46). In addition, exogenous systemic administration of IGF1 increases the rate of skeletal muscle functional recovery after injury (47), improves contractile function $(48,49)$ and fatigue resistance, and induces an increase in muscle oxidative enzymes (47).

Our study has several strong points, particularly the large size of the study population, the large age range and its external validity, i.e. the included subjects representing the general population. The number of oldest-old subjects included in our study is significantly higher than other studies. Therefore, we conclude that our study is very comprehensive with a large number of subjects $(n=944$, age range $38-89$ years) and the largest number of oldest-old subjects $(n=272$, all aged 89 years). Furthermore, handgrip strength is a reliable tool to measure overall muscle strength (21-23). However, this study was set up in a cross-sectional way, and IGF1 and IGFBP 3 were only measured at one time point in both study cohorts. Future longitudinal analysis in our middle-aged-old cohort will allow for further insight into the association of $\mathrm{GH}$ and muscle strength as well as functional performance and ability. We were unable to measure body composition, because the oldest-old subjects were visited at their home. Furthermore, we did not control for additional factors that could potentially influence the associations between the somatotropic axis and muscle strength, such as sex hormones, which were not available due to sample limitations. Finally, the relationship between serum and muscle IGF1 is not necessarily strong, because of different isoforms in muscle and liver $(50,51)$ and we were not able to assess muscle IGF1 directly. Also, we have not measured IGF1 bioactivity (52) as a possibly more accurate measure of IGF1 biological activity.

In summary, we found an association between serum IGF1 levels and handgrip strength in middle-aged-old postmenopausal and oldest-old women, but not in men.
Maintenance of higher IGF1 levels could therefore contribute to preservation of muscle function and subsequent muscle performance in an elderly female population. Further research is needed to address gender differences in IGF1 signaling in muscle in oldest-old subjects.

\section{Declaration of interest}

The authors declare that there is no conflict of interest that could be perceived as prejudicing the impartiality of the research reported.

\section{Funding}

This study was supported by an unrestricted grant from The Netherlands Organization of Scientific Research (ZonMw), the Ministry of Health, Welfare and Sports, The Netherlands Genomics Initiative/Netherlands Organization for scientific research (NGI/NWO; 05040202 and 050-060-810 Netherlands Consortium for Healthy Aging (NCHA)) and the seventh framework program MYOAGE (HEALTH-2007-2.4.5-10).

\section{References}

1 Fisher AL. Of worms and women: sarcopenia and its role in disability and mortality. Journal of the American Geriatrics Society 200452 1185-1190. (doi:10.1111/j.1532-5415.2004.52320.x)

2 Ling CHY, Taekema D, de Craen AJM, Gussekloo J, Westendorp RGJ $\&$ Maier AB. Handgrip strength and mortality in the oldest old. The Leiden 85-plus Study. CMAJ: Canadian Medical Association Journal 2010182 429-435. (doi:10.1503/cmaj.091278)

3 Taekema DG, Gussekloo J, Maier AB, Westendorp RGJ \& de Craen AJM. Handgrip strength as a predictor of functional, psychological and social health. A prospective population based study among the oldest old. Age and Ageing 201039 331-337. (doi:10.1093/ageing/afq022)

4 Doherty TJ. Invited review: aging and sarcopenia. Journal of Applied Physiology 200395 1717-1727. (doi:10.1152/japplphysiol. 00347.2003 )

5 World Population Ageing: 1950-2050. pp 23. New York: United Nations Population Publication, 2002.

6 Sherlock M \& Toogood AA. Aging and the growth hormone/ insulin like growth factor-1 axis. Pituitary $2007 \mathbf{1 0} 189-203$. (doi:10.1007/s11102-007-0039-5)

7 Giovannini S, Marzetti E, Borst SE \& Leeuwenburgh C. Modulation of GH/IGF-1 axis: potential strategies to counteract sarcopenia in older adults. Mechanisms of Ageing and Development 2008129 593-601. (doi:10.1016/j.mad.2008.08.001)

8 Woodhouse LJ, Mukherjee A, Shalet SM \& Ezzat S. The influence of growth hormone status on physical impairments, functional limitations, and health related quality of life in adults. Endocrine Reviews 200626 287-317. (doi:10.1210/er.2004-0022)

9 Onder G, Liperoti R, Russo A, Soldato M, Capoluongo E, Volpato S, Cesari M, Ameglio F, Bernabei R \& Landi F. Body mass index, free insulin-like growth factor I, and physical function among older adults: results from the ilSIRENTE study. American Journal of Physiology. Endocrinology and Metabolism 2006291 E829-E834. (doi:10.1152/ajpendo.00138.2006)

10 Cappola AR, Bandeen-Roche K, Wand GS, Volpato S \& Fried LP. Association of IGF-I levels with muscle strength and mobility in older women. Journal of Clinical Endocrinology and Metabolism 2001 86 4139-4146. (doi:10.1210/jc.86.9.4139)

11 Kaplan RC, McGinn AP, Pollak MN, Kuller L, Strickler HD, Rohan TE, Xue X, Kritchevsky SB, Newman AB \& Psaty BM. Total insulin like growth factor 1 and insulin like growth factor binding 
protein levels, functional status, and mortality in older adults. Journal of the American Geriatrics Society 200856 652-660. (doi:10.1111/j.1532-5415.2007.01637.x)

12 Roubenoff R, Parise H, Payette HA, Abad LW, D'Agostino R, Jacques PF, Wilson PWF, Dinarello CA \& Harris TB. Cytokines, insulin-like growth factor 1 , sarcopenia, and mortality in very old community-dwelling men and women: the Framingham Heart Study. American Journal of Medicine 2003115 429-435. (doi:10. 1016/j.amjmed.2003.05.001)

13 Papadakis MA, Grady D, Black D, Tierney MJ, Gooding GAW, Schambelan M \& Grunfeld C. Growth hormone replacement in healthy older men improves body composition but not functional ability. Annals of Internal Medicine $1996 \mathbf{1 2 4} 708-716$.

14 White HK, Petrie CD, Landschulz W, MacLean D, Taylor A, Lyles K, Wei JY, Hoffman AR, Salvatori R, Ettinger MP, Morey MC, Blackman MR, Merriam GR \& for the Capromorelin Study Group. Effects of an oral growth hormone secretagogue in older adults. Journal of Clinical Endocrinology and Metabolism 200994 1198-1206. (doi:10.1210/jc.2008-0632)

15 Sattler FR, Castaneda-Sceppa C, Binder EF, Schroeder ET, Wang Y, Bhasin S, Kawakubo M, Stewart Y, Yarasheski KE, Ulloor J, Colletti P, Roubenoff R \& Azen SP. Testosterone and growth hormone improve body composition and muscle performance in older men. Journal of Clinical Endocrinology and Metabolism 2009 94 1991-2001. (doi:10.1210/jc.2008-2338)

16 Westendorp RGJ, van Heemst D, Rozing MP, Frölich M, Mooijaart SP, Blauw GJ, Beekman M, Heijmans BT, de Craen AJM, Slagboom PE \& for the Leiden Longevity Study Group. Nonagenarian siblings and their offspring display lower risk of mortality and morbidity than sporadic nonagenarians: the Leiden Longevity Study. Journal of the American Geriatrics Society 200957 1634-1637. (doi:10.1111/j.1532-5415.2009.02381.x)

17 Bootsma-van der Wiel A, van Exel E, de Craen AJM, Gussekloo J, Lagaay AM, Knook DL \& Westendorp RGJ. A high response is not essential to prevent selection bias: results from the Leiden 85-plus Study. Journal of Clinical Epidemiology $2002 \quad 55$ 1119-1125. (doi:10.1016/S0895-4356(02)00505-X)

18 Andreassen M, Raymond I, Hildebrandt P, Kistorp C, Rathcke C, Vestergaard H, Faber J \& Østergaard Kristensen L. Associations between plasma insulin-like growth factor-I and the markers of inflammation interleukin 6, C-reactive protein and YKL-40 in an elderly background population. Inflammation Research $2010 \mathbf{5 9}$ 503-510. (doi:10.1007/s00011-009-0154-z)

19 Lauretani F, Russo CR, Bandinelli S, Bartali B, Cavazzini C, Di Iorio A, Corsi AM, Rantanen T, Guralnik JM \& Ferrucci L. Age-associated changes in skeletal muscles and their effect on mobility: an operational diagnosis of sarcopenia. Journal of Applied Physiology 200395 1851-1860. (doi:10.1152/japplphysiol. $00246.2003)$

20 Abellan van Kan G, André E, Bischoff Ferrari HA, Boirie Y, Onder G, Pahor M, Ritz P, Rolland Y, Sampaio C, Studenski S, Visser M \& Vellas B. Carla task force on sarcopenia: propositions for clinical trials. Journal of Nutrition, Health and Aging 200913 700-707. (doi:10.1007/s12603-009-0200-0)

21 Peolsson A, Hedlund R \& Oberg B. Intra- and inter-tester reliability and reference values for hand strength. Journal of Rehabilitation Medicine 200133 36-41. (doi:10.1080/165019701300006524)

22 Luna-Heredia E, Martín-Peňa G \& Ruiz-Galiana J. Handgrip dynamometry in healthy adults. Clinical Nutrition $2005 \mathbf{2 4}$ 250-258. (doi:10.1016/j.clnu.2004.10.007)

23 Budziareck MB, Pureza Duarte RR \& Barbosa-Silva MC. Reference values and determinants for handgrip strength in healthy subjects. Clinical Nutrition 200827 357-362. (doi:10.1016/ j.clnu.2008.03.008)

24 Kempen GI, Miedema I, Ormel J \& Molenaar W. The assessment of disability with the Groningen Activity Restriction Scale. Conceptual framework and psychometric properties. Social Science and Medicine 199643 1601-1610. (doi:10.1016/S0277-9536(96)00057-3)

25 Guralnik JM, Simonsick EM, Ferrucci L, Glynn RJ, Berkman LF, Blazer DG, Scherr PA \& Wallace RB. A short physical performance battery assessing lower extremity function: association with self reported disability and prediction of mortality and nursing home admission. Journal of Gerontology 199449 M85-M94. (doi:10. 1093/geronj/49.2.M85)

26 Goldspink G. Loss of muscle strength during aging studied at the gene level. Rejuvenation Research 200710 397-405. (doi:10. 1089/rej.2007.0597)

27 Ohlsson C, Mohan S, Sjögren K, Tivesten A, Isgaard J, Isaksson O, Jansson JO \& Svensson J. The role of liver-derived insulin-like growth factor-I. Endocrine Reviews 200930 494-535. (doi:10. 1210/er.2009-0010)

28 Laviola L, Natalicchio A, Perrini S \& Giorgino F. Abnormalities of IGF-I signaling in the pathogenesis of diseases of the bone, brain, and fetoplacental unit in humans. American Journal of Physiology. Endocrinology and Metabolism 2008295 E991-E999. (doi:10. 1152/ajpendo.90452.2008)

29 Li M, Li C \& Parkhouse WS. Age-related differences in the des IGF-I-mediated activation of Akt-1 and p70 S6K in mouse skeletal muscle. Mechanisms of Ageing and Development 2003 124 771-778. (doi:10.1016/S0047-6374(03)00124-6)

30 Sell C, Ptasznik A, Chang CD, Swantek J, Cristofalo VJ \& Baserga R. IGF-1 receptor levels and the proliferation of young and senescent human fibroblasts. Biochemical and Biophysical Research Communications 1993194 259-265. (doi:10.1006/bbrc.1993.1813)

31 Perrini S, Laviola L, Carreira MC, Cignarelli A, Natalicchio A \& Giorgino F. The GH/IGF1 axis and signaling pathways in the muscle and bone: mechanisms underlying age-related skeletal muscle wasting and osteoporosis. Journal of Endocrinology 2010 205 201-210. (doi:10.1677/JOE-09-0431)

32 Kostka T, Arsac LM, Patricot MC, Berthouze SE, Lacour JR \& Bonnefoy M. Leg extensor power and dehydroepiandrosterone sulfate, insulin-like growth factor-I and testosterone in healthy active elderly people. European Journal of Applied Physiology 2000 82 83-90. (doi:10.1007/s004210050655)

33 Orsatti FL, Nahas EAP, Maesta N, Nahas-Neto J \& Burini RC. Plasma hormones, muscle mass and strength in resistance-trained postmenopausal women. Maturitas 200859 394-404. (doi:10. 1016/j.maturitas.2008.04.002)

34 Rudman D, Kutner MH, Rogers CM, Lubin MF, Fleming GA \& Bain RP. Impaired growth hormone secretion in the adult population: relation to age and adiposity. Journal of Clinical Investigation 198167 1361-1369. (doi:10.1172/JCI110164)

35 Landin-Wilhelmsen K, Wilhelmsen L, Lappas G, Rosén T, Lindstedt G, Lundberg PA \& Bengtsson BA. Serum insulin-like growth factor $I$ in a random population sample of men and women: relation to age, sex, smoking habits, coffee consumption and physical activity, blood pressure and concentrations of plasma lipids, fibrinogen, parathyroid hormone and osteocalcin. Clinical Endocrinology 199441 351-357. (doi:10.1111/j.1365-2265. 1994.tb02556.x)

36 Leifke E, Gorenoi V, Wichers C, Von Zur Mühlen A, Von Büren E \& Brabant G. Age-related changes of serum sex hormones, insulinlike growth factor-1 and sex-hormone binding globulin levels in men: cross-sectional data from a healthy male cohort. Clinical Endocrinology 200053 689-695. (doi:10.1046/j.1365-2265. 2000.01159.x)

37 Jakobsdóttir S, van Nieuwpoort IC, Schaap LA, van Schoor NM, Lips P \& Drent ML. Serum insulin-like growth factor-I and body composition in community dwelling older people. Clinical Endocrinology 201073 173-180. (doi:10.1111/j.1365-2265. 2009.03747.x)

38 Yamamoto H, Sohmiya M, Oka N \& Kato Y. Effects of aging and sex on plasma insulin-like growth factor I (IGF-I) levels in normal adults. Acta Endocrinologica 1991124 497-500. (doi:10.1530/ acta.0.1240497)

39 Friedrich N, Krebs A, Nauck M \& Wallaschofski H. Age- and gender-specific reference ranges for serum insulin-like growth factor I (IGF-I) and IGF-binding protein-3 concentrations on the Immulite 2500: results of the Study of Health in Pomerania (SHIP). Clinical Chemistry and Laboratory Medicine $2010 \mathbf{4 8}$ 115-120. (doi:10.1515/CCLM.2010.009) 
40 Baumgartner RN, Waters DL, Gallagher D, Morley JE \& Garry PJ. Predictors of skeletal muscle mass in elderly men and women. Mechanisms of Ageing and Development $1999 \quad \mathbf{1 0 7}$ 123-136. (doi:10.1016/S0047-6374(98)00130-4)

41 Gläser S, Friedrich N, Ewert R, Schäper C, Krebs A, Dörr M, Völzke H, Felix SB, Nauck M, Wallaschofski H \& Koch B. Association of circulating IGF-I and IGFBP-3 concentrations and exercise capacity in healthy volunteers: results of the Study of Health in Pomerania. Growth Hormone and IGF Research 201020 404-410. (doi:10.1016/j.ghir.2010.09.002)

42 Cappola AR, Xue QL \& Fried LP. Multiple hormonal deficiencies in anabolic hormones are found in frail older women: the Women's Health and Aging Studies. Journals of Gerontology. Series A, Biological Sciences and Medical Sciences 2009 64A 243-248. (doi:10.1093/gerona/gln026)

43 Harris TB, Kiel D, Roubenoff R, Langlois J, Hannan M, Havlik R \& Wilson P. Association of insulin-like growth factor-I with body composition, weight history, and past health behaviors in the very old: the Framingham Heart Study. Journal of the American Geriatrics Society $1997 \mathbf{4 5} 133-139$.

44 Boonen S, Lysens R, Verbeke G, Joosten E, Dejaeger E, Pelemans W, Flamaing J \& Bouillon R. Relationship between age-associated endocrine deficiencies and muscle function in elderly women: a cross-sectional study. Age and Ageing 199827 449-454. (doi:10. 1093/ageing/27.2.231)

45 Kiel DP, Puhl J, Rosen CJ, Berg K, Murphy JB \& MacLean DB. Lack of an association between insulin-like growth factor-I and body composition, muscle strength, physical performance or self-reported mobility among older persons with functional limitations. Journal of the American Geriatrics Society 199846 822-828.

46 Short KR, Moller N, Bigelow ML, Coenen-Schimke J \& Nair KS. Enhancement of muscle mitochondrial function by growth hormone. Journal of Clinical Endocrinology and Metabolism 2008 93 597-604. (doi:10.1210/jc.2007-1814)
47 Schertzer JD, Ryall JG \& Lynch GS. Systemic administration of IGF-I enhances oxidative status and reduces contraction-induced injury in skeletal muscles of $\mathrm{mdx}$ dystrophic mice. American Journal of Physiology. Endocrinology and Metabolism 2006291 E499-E505. (doi:10.1152/ajpendo.00101.2006)

48 Lynch GS, Cuffe SA, Plant DR \& Gregorevic P. IGF-I treatment improves the functional properties of fast- and slow-twitch skeletal muscles from dystrophic mice. Neuromuscular Disorders 200111 260-268. (doi:10.1016/S0960-8966(00)00192-9)

49 Gregorevic P, Plant DR, Leeding KS, Bach LA \& Lynch GS. Improved contractile function of the $\mathrm{mdx}$ dystrophic mouse diaphragm muscle after insulin-like growth factor-I administration. American Journal of Pathology $20021612263-2272$.

50 Yang S, Alnaqeeb M, Simpson H \& Goldspink G. Cloning and characterization of an IGF-1 isoform expressed in skeletal muscle subjected to stretch. Journal of Muscle Research and Cell Motility 199617 487-495. (doi:10.1007/BF00123364)

51 Loughna PT, Mason P \& Bates PC. Regulation of insulin-like growth factor 1 gene expression in skeletal muscle. Symposia of the Society for Experimental Biology 199246 319-330.

52 Brugts MP, Ranke MB, Hofland LJ, van der Wansem K, Weber K, Frystyk J, Lamberts SW \& Janssen JA. Normal values of circulating insulin-like growth factor-I bioactivity in the healthy population: comparison with five widely used IGF-I immunoassays. Journal of Clinical Endocrinology and Metabolism 200893 2539-2545. (doi:10.1210/jc.2007-2454)

Received 25 November 2010

Accepted 1 December 2010 